\title{
(2) OPEN ACCESS \\ Pathological findings of hypertrophic pachymeningitis associated with eosinophilic granulomatosis with polyangiitis
}

\author{
Wataru Shiraishi (ㄷ, ${ }^{1}$ Yoshitaka Tsujimoto, ${ }^{2}$ Tomoko Shiraishi ${ }^{3}$
}

'Department of Neurology, Kokura Memorial Hospital, Kitakyushu, Japan

${ }^{2}$ Department of Neurosurgery, Kokura Memorial Hospital, Kitakyushu, Japan

${ }^{3}$ Shiraishi Internal Medicine Clinic, Nogata, Japan

Correspondence to DrWataru Shiraishi; watarus@neuro.med.kyushu-u. ac.jp

Accepted 24 August 2021

Check for updates

(c) BMJ Publishing Group Limited 2021. Re-use permitted under CC BY-NC. No commercial re-use. See rights and permissions. Published by BMJ.

To cite: Shiraishi W, Tsujimoto Y, Shiraishi T. BMJ Case Rep 2021:14:e243395. doi:10.1136/bcr-2021-

243395

\section{SUMMARY}

The most common neurological manifestation of eosinophilic granulomatosis with polyangiitis (EGPA), formerly called Churg-Strauss syndrome, is mononeuritis multiplex caused by small-vessel vasculitis. In contrast, central nervous system involvement is rare. Among EGPA-associated central nervous system disorders, there are only a few reported cases of hypertrophic pachymeningitis (HP). Here, we report a patient with EGPA with headache and ophthalmoplegia who presented with HP and had a dural biopsy. The biopsy specimen showed lymphocytic inflammatory cell infiltration without EGPA-specific findings, that is, eosinophilic infiltration, granuloma or angiitis. To the best of our knowledge, there are no previous reports of EGPAassociated HP pathology. Here, we report the first case presentation of a patient with EGPA-associated HP with pathological findings.

\section{BACKGROUND}

Eosinophilic granulomatosis with polyangiitis (EGPA) is an antineutrophil cytoplasm antibody (ANCA)-associated systematic necrotising vasculitis characterised by eosinophilic granulomatous inflammation and small-vessel vasculitis. ${ }^{1}$ EGPA was first described by Churg and Strauss in $1951^{2}$ and was formerly called Churg-Strauss syndrome. The most common neurological manifestation of EGPA is mononeuritis multiplex caused by small-vessel vasculitis, ${ }^{3}$ while cerebral lesions are rare $(3 \%-5 \%$ of cases). ${ }^{4}$ Conversely, hypertrophic pachymeningitis $(\mathrm{HP})$ is a rare inflammatory disorder demonstrating thickening of the intracranial or spinal dura mater. HP pathology shows dural interstitial fibrosis and inflammatory cell infiltration consisting mainly of lymphocytes. ${ }^{5} \mathrm{HP}$ is aetiologically heterogeneous, and causes include autoimmune diseases, infection, trauma and malignancies. The most frequent form is ANCA-related HP. ${ }^{6}$ Among ANCA-related HP, myeloperoxidase-ANCA-related $\mathrm{HP}$ is the most common, while EGPA-associated HP is rare. Here, we present the first case report of EGPA-associated HP with pathological findings.

\section{CASE PRESENTATION}

A 78-year-old Japanese man visited our hospital with a 2-week history of left temporal headache and a 2-day history of diplopia. He had lost $2 \mathrm{~kg}$ of body weight in 1 month. His medical history included allergic rhinitis for more than 20 years and a 6-month history of uveitis treated with steroid eyedrops. He was a current smoker of 2 packs a day for more than 50 years. He had no notable family history. On physical examination, he showed a left temporal headache with a numerical rating scale of $6 / 10$ and right abducens nerve palsy (figure 1) with right gaze diplopia. The patient did not show cranial nerve palsy, except from the abducens nerve. He showed no deafness or tinnitus. In the four extremities, the manual muscle test was normal, but decreased sensation was observed in the left medial lower extremity in the saphenous nerve region. $\mathrm{He}$ showed no ataxia or autonomic dysfunction. He had no generalised malaise, abnormal respiratory sounds, limb swelling, arthritis or purpura.

\section{INVESTIGATIONS}

An initial blood test showed a raised total white blood cell count with hypereosinophilia $\left(8.9 \times 10^{9}\right.$ white blood cells/L, $1.36 \times 10^{9}$ eosinophils/L; $15.3 \%)$, accompanied by an inflammatory response with elevated $\mathrm{C}$ reactive protein levels $(15 \mathrm{mg} / \mathrm{L}$, normal $<5 \mathrm{mg} / \mathrm{L})$ and erythrocyte sedimentation rate $(81 \mathrm{~mm} /$ hour, normal $<15 \mathrm{~mm} /$ hour). Urinalysis, electrolytes, thyroid function, liver enzymes and renal function were unremarkable. IgE $(88 \mathrm{IU} / \mathrm{mL}$, normal $<170 \mathrm{IU} / \mathrm{mL}), \operatorname{IgG} 4$ $(42.8 \mathrm{mg} / \mathrm{dL}$, normal $<121 \mathrm{mg} / \mathrm{dL})$, rheumatoid factor $(0 \mathrm{IU} / \mathrm{mL})$, myeloperoxidase-ANCA $(<1.0 \mathrm{U} /$ $\mathrm{mL})$ and proteinase-3-ANCA $(<1.0 \mathrm{U} / \mathrm{mL})$ were not detected. Mycobacterium tuberculosis-specific interferon- $\gamma$ test was negative. $\beta$ - $D$ glucan was not elevated. Cerebrospinal fluid (CSF) analysis showed mild elevation of CSF protein $(0.49 \mathrm{~g} / \mathrm{L}$, normal $<0.4 \mathrm{~g} / \mathrm{L}$ ) without pleocytosis. CSF was also negative for oligoclonal IgG bands, myelin basic protein and elevation of the IgG index $(0.45$, normal <0.73). Electroencephalography revealed normal findings without any spikes, sharp waves or slow waves. A nerve conduction study of the four extremities was normal. Plain head MRI showed no brain parenchymal abnormalities but revealed maxillary sinusitis (figure 2A-C). Gadoliniumenhanced brain MRI revealed focal enhancement of the dura matter (figure 2D) around the left temporal lobe. Whole-body CT showed pulmonary nodules and opacities (figure 2E) without any signs of malignancy. A dura mater biopsy was performed from the left temple, and the specimen showed inflammatory cell infiltration of the dura mater. Blood vessel infiltration of inflammatory cells, granuloma formation, eosinophil invasion and fibrous tissue growth were scarce (figure 3), indicating potential early-phase HP. 


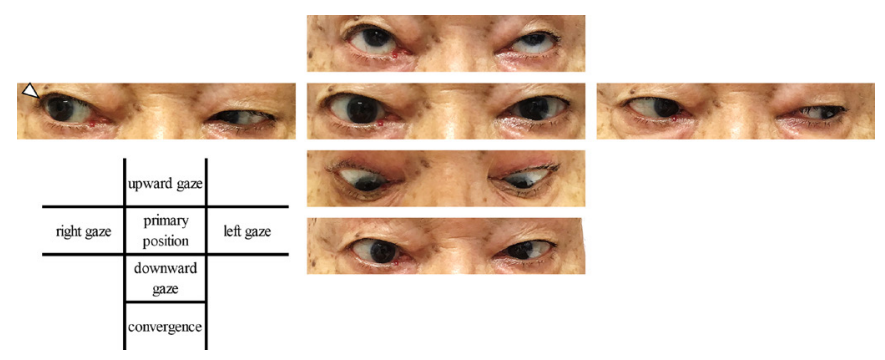

Figure 1 Photographs of ocular movements on admission. Mild right abducens nerve palsy was noted (arrowhead).

Immunohistological findings revealed the predominant infiltration of cluster of differentiation (CD)3-positive T lymphocytes. CD20-positive B lymphocytes and CD68-positive macrophages were also found, but they were scarce. There were few multiple myeloma oncogene 1-positive plasma cells (figure 4). We did not perform IgG4 staining due to the scarcity of plasma cells.

\section{DIFFERENTIAL DIAGNOSIS}

Possible causes of HP include IgG4-related diseases, ANCAassociated diseases, idiopathic disease, malignancies, tuberculosis and fungal infection. ${ }^{6}$ We performed a dural biopsy to distinguish these differential diagnoses, and the patient's pathological findings demonstrated no evidence of malignancy or infection. The dural biopsy specimen showed lymphocytic infiltration, which is compatible with HP pathology, ${ }^{5}$ but had no diseasespecific findings.

We also investigated the pathogenesis of HP in this patient. According to his history of chronic sinusitis and hypereosinophilia, EGPA was one of the main differential diagnoses. The most common diagnostic criteria of EGPA are those of the American College of Rheumatologists, which require the presence of four of the six following factors for a definite diagnosis: asthma, eosinophils (>10\%), neuropathy, pulmonary infiltrates,

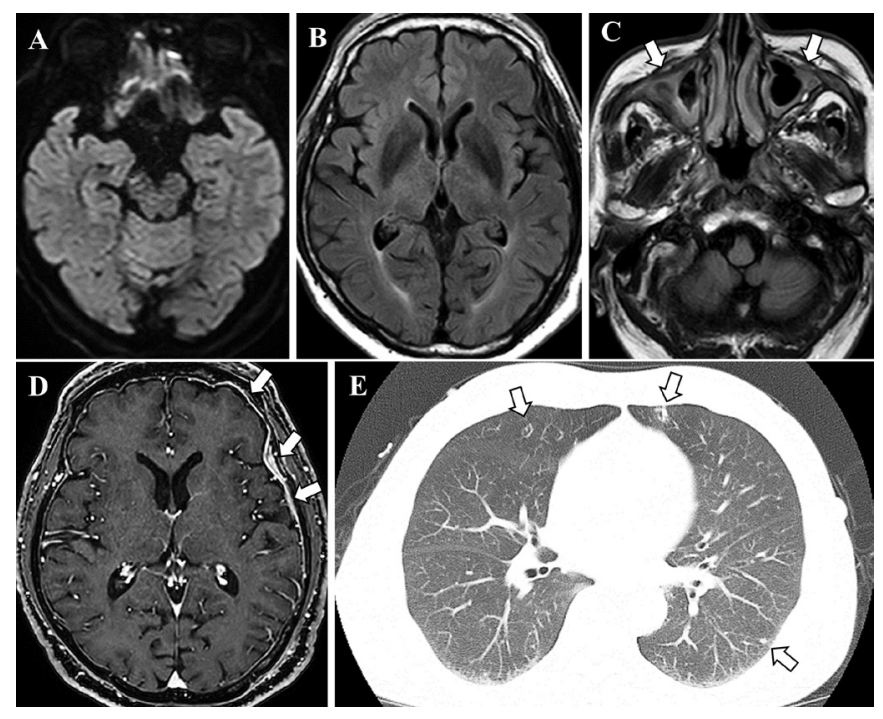

Figure 2 Non-enhanced brain MRI (A-C), enhanced brain MRI (D) and chest $C T(E)$. Brain diffusion-weighted MRI $(A)$ and fluid-attenuated inversion recovery $\mathrm{MRI}(\mathrm{B}, \mathrm{C})$ showed no parenchymal abnormalities. However, maxillary sinusitis was observed ( $C$, arrows). Gadoliniumenhanced T1-weighted MRI demonstrated hypertrophic pachymeningitis around the left temporal lobe ( $D$, arrows). Chest $C T$ revealed multiple nodular shadows (E, arrows).
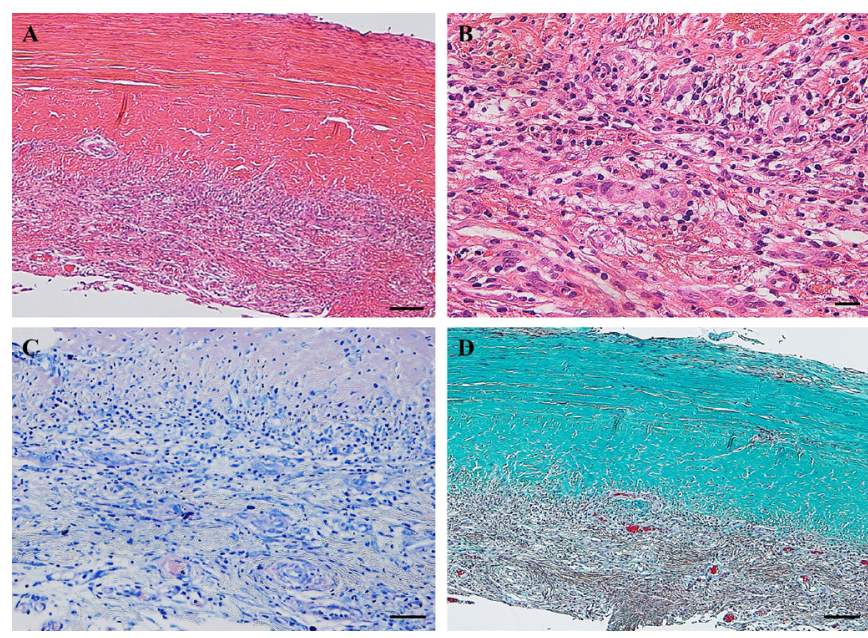

Figure 3 Dural biopsy specimens from the thickened dura mater. H\&E staining showed infiltration of inflammatory cells, but eosinophils were scarce $(A, B)$. Periodic acid Schiff staining did not reveal any findings of infectious hypertrophic pachymeningitis, including fungal infections (C). Masson trichrome staining did not show the presence of elastic fibre growth (D). Scale bars: $100 \mu \mathrm{m}(A, D), 20 \mu \mathrm{m}(B)$ and $50 \mu \mathrm{m}(D)$.

paranasal sinus disease and extravascular eosinophils. ${ }^{7}$ Our case presented with hypereosinophilia, abducens nerve neuropathy, pulmonary infiltrates and sinusitis, which are compatible with a diagnosis of EGPA according to these criteria.

\section{OUTCOME AND FOLLOW-UP}

Oral acetaminophen alleviated his headache symptoms. However, blood tests showed residual hypereosinophilia and inflammatory responses ( $C$ reactive protein $5-10 \mathrm{mg} / \mathrm{L}$, erythrocyte sedimentation rate $\sim 50 \mathrm{~mm} /$ hour). After the dural biopsy, we started oral steroid treatment (15 $\mathrm{mg} /$ day prednisolone), resulting in a rapid improvement of the abducens nerve palsy, headache and inflammatory response in the blood. As the symptoms resolved with oral steroid only, we did not administer immunosuppressant or antibody drugs. We are currently observing the clinical course of his symptoms while tapering prednisolone. When the

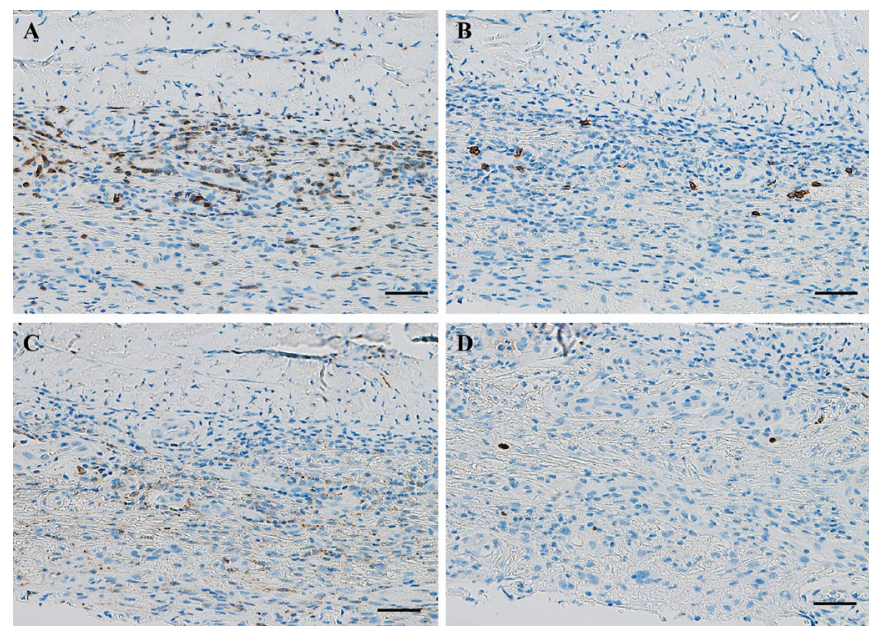

Figure 4 Immunostaining showed the infiltration of CD3-positive T lymphocytes (A). Some CD20-positive B lymphocytes were also found (B). CD68-positive macrophage infiltration was low (C), and multiple myeloma oncogene-1-positive plasma cell infiltration was observed scarcely (D). Scale bars: $50 \mu \mathrm{m}$. CD, cluster of differentiation. 
prednisolone dose was tapered to $7.5 \mathrm{mg} / \mathrm{day}$, the headache and serum inflammatory response flared up, and we continued prednisolone $10 \mathrm{mg} /$ day.

\section{DISCUSSION}

HP is a rare inflammatory disorder demonstrating local or diffuse thickening of the intracranial or spinal dura mater. Yonekawa et al reported that its prevalence was 0.949/100 $000 .^{6}$ The most common cause of HP is ANCA-associated vasculitis, whereas infection-associated and malignancy-associated HP are relatively rare. ${ }^{6}$ While most HP cases have ANCA-related vasculitis, only two cases presenting with EGPA-associated HP have been described. ${ }^{8}$ Nakano et al reported an ANCA-negative 42-year-old man with elevated IgE who was treated with oral prednisolone and cyclophosphamide. ${ }^{8}$ Lio et al reported an ANCA-negative 47-year-old female patient with chronic sinusitis and HP who was treated with oral prednisolone and cyclophosphamide. ${ }^{9}$ Both of these cases were ANCA-negative EGPA. Sada et al reported that the ANCA positivity rate in EGPA is about $50 \% .{ }^{10}$ Therefore, ANCA negativity is not considered to be a negative sign for EGPA. The relationship between EGPA and HP is still unclear. Sada et al reported that the prevalence of EGPA was $1.78 / 100000 .{ }^{10}$ From this, a simple prevalence-based calculation gives a 1.69/10 000000000 chance of the accidental association of EGPA and HP. Since there have now been three reports, including our case, their association by chance is unlikely, so it is suspected that there is some relationship between EGPA and HP. The pathological findings of this case showed no increase in elastic fibres, indicating that he had early-stage HP. Generally speaking, in the dural pathology of HP, even HP associated with ANCA-related vasculitis or IgG4-related disease, the findings are often not specific for the underlying pathogenic

\section{Learning points}

- The most common causes of hypertrophic pachymeningitis (HP) include antineutrophil cytoplasm antibody-related diseases, IgG4-related diseases, idiopathic disease, fungal infection and malignancy.

- Eosinophilic granulomatosis with polyangiitis (EGPA) can be a rare cause of HP.

- This is the first biopsy case of EGPA-associated HP, and the dural pathology showed no disease-specific findings of EGPA, such as eosinophil infiltration, granuloma or vasculitis.

- Non-specific pathological findings cannot rule out EGPA.

- Our case responded well to steroid therapy; however, previous reports of EGPA-associated HP required immunosuppressants. factors. ${ }^{511}$ Therefore, although the dural biopsy findings in this case were not EGPA-specific, they do not indicate the lack of a relationship between EGPA and HP. This is the first report of a biopsy of EGPA-associated HP, and the findings indicate the importance of accumulating similar cases.

Acknowledgements We thank Dr Kenichiro Murata, Department of Pathology, Kokura Memorial, for the pathological investigations.

Contributors WS contributed to data collection and writing the manuscript. YT contributed to the management of the case and data collection. TS contributed to data collection and interpretation of the chest CT.

Funding The authors have not declared a specific grant for this research from any funding agency in the public, commercial or not-for-profit sectors.

Competing interests None declared.

Patient consent for publication Obtained.

Provenance and peer review Not commissioned; externally peer reviewed.

Open access This is an open access article distributed in accordance with the Creative Commons Attribution Non Commercial (CC BY-NC 4.0) license, which permits others to distribute, remix, adapt, build upon this work non-commercially, and license their derivative works on different terms, provided the original work is properly cited and the use is non-commercial. See: http://creativecommons.org/ licenses/by-nc/4.0/.

ORCID iD

Wataru Shiraishi http://orcid.org/0000-0001-8528-2622

\section{REFERENCES}

1 Furuta S, Iwamoto T, Nakajima H. Update on eosinophilic granulomatosis with polyangiitis. Allergol Int 2019;68:430-6.

2 Churg J, Strauss L. Allergic granulomatosis, allergic angiitis, and periarteritis nodosa. Am J Pathol 1951;27:277-301.

3 Samson M, Puéchal $X$, Devilliers $H$, et al. Mononeuritis multiplex predicts the need for immunosuppressive or immunomodulatory drugs for EGPA, pan and MPA patients without poor-prognosis factors. Autoimmun Rev 2014;13:945-53.

4 André R, Cottin V, Saraux J-L, et al. Central nervous system involvement in eosinophilic granulomatosis with polyangiitis (Churg-Strauss): report of 26 patients and review of the literature. Autoimmun Rev 2017;16:963-9.

5 Kupersmith MJ, Martin V, Heller G, et al. Idiopathic hypertrophic pachymeningitis. Neurology 2004;62:686-94.

6 Yonekawa T, Murai H, Utsuki S, et al. A nationwide survey of hypertrophic pachymeningitis in Japan. J Neurol Neurosurg Psychiatry 2014;85:732-9.

7 Masi AT, Hunder GG, Lie JT, et al. The American College of rheumatology 1990 criteria for the classification of Churg-Strauss syndrome (allergic granulomatosis and angiitis). Arthritis Rheum 1990:33:1094-100.

8 Nakano Y, Miyawaki Y, Sada K-E, et al. Development of hypertrophic pachymeningitis in a patient with antineutrophil cytoplasmic antibody-negative eosinophilic granulomatosis with polyangiitis. J Clin Rheumatol 2019;25:e61.

9 Lio M, Fukuda S, Maguchi S, et al. Churg-Strauss syndrome with pachymeningitis refractory to steroid therapy atone--a case report. Auris Nasus Larynx 2001;28 Suppl:S121-5.

10 Sada K-E, Amano K, Uehara R, et al. A nationwide survey on the epidemiology and clinical features of eosinophilic granulomatosis with polyangiitis (Churg-Strauss) in Japan. Mod Rheumatol 2014:24:640-4

11 De Virgilio A, de Vincentiis M, Inghilleri M, et al. Idiopathic hypertrophic pachymeningitis: an autoimmune IgG4-related disease. Immunol Res 2017;65:386-94 
Copyright 2021 BMJ Publishing Group. All rights reserved. For permission to reuse any of this content visit https://www.bmj.com/company/products-services/rights-and-licensing/permissions/

BMJ Case Report Fellows may re-use this article for personal use and teaching without any further permission.

Become a Fellow of BMJ Case Reports today and you can:

- Submit as many cases as you like

- Enjoy fast sympathetic peer review and rapid publication of accepted articles

Access all the published articles

Re-use any of the published material for personal use and teaching without further permission

Customer Service

If you have any further queries about your subscription, please contact our customer services team on +44 (0) 2071111105 or via email at support@bmj.com.

Visit casereports.bmj.com for more articles like this and to become a Fellow 